\title{
Second pilot trials of the STAR-Liege protocol for tight glycemic control in critically ill patients
}

\author{
Sophie Penning ${ }^{2 *}$, Aaron J Le Compte ${ }^{1}$, Paul Massion ${ }^{6}$, Katherine T Moorhead ${ }^{2}$, Christopher G Pretty ${ }^{2}$,
} Jean-Charles Preiser ${ }^{3}$, Geoffrey M Shaw ${ }^{4,5}$, Fatanah Suhaimi ${ }^{1}$, Thomas Desaive ${ }^{2}$ and J Geoffrey Chase ${ }^{1}$

\author{
* Correspondence: \\ sophie.penning@ulg.ac.be \\ ${ }^{2}$ Cardiovascular Research Centre, \\ Institut de Physique, Université de \\ Liege, Institut de Physics, Allée du 6 \\ Août, 17 (Bât B5), Liege B4000 \\ Liege, Liege, Belgium \\ Full list of author information is \\ available at the end of the article
}

\begin{abstract}
Background: Critically ill patients often present increased insulin resistance and stress-induced hyperglycemia. Tight glycemic control aims to reduce blood glucose (BG) levels and variability while ensuring safety from hypoglycemia. This paper presents the results of the second Belgian clinical trial using the customizable STAR framework in a target-to-range control approach. The main objective is reducing measurement frequency while maintaining performance and safety of the glycemic control.

Methods: The STAR-Liege 2 (SL2) protocol targeted the 100-140 mg/dL glycemic band and offered 2-hourly and 3-hourly interventions. Only insulin rates were adjusted, and nutrition inputs were left to the attending clinicians. This protocol restricted the forecasted risk of $B G<90 \mathrm{mg} / \mathrm{dL}$ to a $5 \%$ level using a stochastic model of insulin sensitivity to assess patient-specific responses to insulin and its future likely variability to optimize insulin interventions. The clinical trial was performed at the Centre Hospitalier Universitaire de Liege and included 9 patients. Results are compared to 24-hour pre-trial and 24-hour post-trial, but also to the results of the first pilot trial performed in Liege, STAR-Liege 1 (SL1). This trial was approved by the Ethics Committee of the Medical Faculty of the University of Liege (Liege, Belgium).
\end{abstract}

Results: During the SL2 trial, 91 measurements were taken over 194 hours. BG levels were tightly distributed: $54.9 \%$ of BG within $100-140 \mathrm{mg} / \mathrm{dL}, 40.7 \%$ were $\geq$ $140 \mathrm{mg} / \mathrm{dL}$ and $4.4 \%$ were $<100 \mathrm{mg} / \mathrm{dL}$ with no BG $<70 \mathrm{mg} / \mathrm{dL}$. Comparing these results with 24-hour pre-trial and post-trial shows that SL2 reduced high and low BG levels and reduced glycemic variability. Nurses selected 3-hourly measurement only 5 of 16 times and overrode $12 \%$ of 91 recommended interventions (35\% increased insulin rates and 65\% decreased insulin rates). SL1 and SL2 present similar BG levels distribution ( $p>0.05$ ) with significantly reduced measurement frequency for SL2 $(p<0.05)$.

Conclusions: The SL2 protocol succeeded in reducing clinical workload while maintaining safety and effectiveness of the glycemic control. SL2 was also shown to be safer and tighter than hospital control. Overall results validate the efficacy of significantly customizing the STAR framework.

Keywords: Glycemic control, Critical care, Intensive care unit, Pilot trial

\section{Biomed Central}

(c) 2012 Penning et al.; licensee BioMed Central Ltd. This is an Open Access article distributed under the terms of the Creative Commons Attribution License (http://creativecommons.org/licenses/by/2.0), which permits unrestricted use, distribution, and reproduction in any medium, provided the original work is properly cited. 


\section{Background}

In critically ill patients, increased insulin resistance due to stress results in stressinduced hyperglycemia, which is linked to worsened patient outcomes and increased mortality [1-4]. Tight glycemic control (TGC) seeks to reduce the blood glucose (BG) levels and variability associated with negative outcomes, and can reduce mortality up to $45 \%$ [5-7]. However, a high risk of hypoglycemia and inability to repeat successful results have been associated with many TGC protocols [8], where limiting low BG levels is crucial to ensure control safety $[3,9,10]$.

High inter- and intra- patient variability makes successful TGC difficult [11-13]. Model-based controllers use computer models of patient physiology to capture patientspecific response to insulin and nutrition inputs. Thus, they enable TGC protocols to predict patient response to optimize interventions and resulting BG levels in the presence of variability [14-17].

STAR (Stochastic TARgeted) is a flexible model-based control approach that enables adaptive, patient-specific TGC. STAR directly accounts for evolving physiological patient condition and inter- and intra- patient variability by identifying insulin sensitivity (SI) and its future variability [11] at each intervention to optimize control and safety. STAR can be customized for clinically specified glycemic targets, control approaches (e.g. insulin only, insulin and nutrition, etc.) and clinical resources (e.g. measurement frequency).

The STAR framework was previously customized in glycemic target and control intervention to match clinical standards at the Centre Hospitalier Universitaire (CHU) of Liege, Belgium [18]. This paper presents a significantly modified and improved STAR-Liege protocol, based on issues highlighted in the first pilot trial results. In particular, only 2 and 3 hourly insulin interventions were offered. The goal was changed to maximize the overlap of the potential $\left(5^{\text {th }}-95^{\text {th }}\right.$ percentile) glycemic outcome range with a clinically specified $100-140 \mathrm{mg} / \mathrm{dL}$ band, a target-to-range approach. In contrast, the prior approach had a specific target $(125 \mathrm{mg} / \mathrm{dL})$ and offered 1-hourly interventions that resulted in 20-24 measurements per day. Finally, the stochastic models were updated to better account for the more variable cardiovascular surgery patient cohort in this intensive care unit (ICU), where recent studies found these patients to be more insulin resistant and variable (greater intra-patient variability), especially for the first days of ICU stay than the overall medical ICU cohort as a whole [13]. Hence, the stochastic model used here directly accounted for this variability by using clinical data specific to cardiac-surgery patients and for the first days of stay. The main objective of these second clinical trials was reducing clinical workload for a highly variable ICU cohort, while maintaining control quality and safety, by using a target-to-range approach.

\section{Method}

\section{STAR-Liege 2 protocol}

Three major changes were made for the STAR-Liege 2 (SL2) protocol. First, the clinically specified glycemic target of $125 \mathrm{mg} / \mathrm{dL}$ was changed to a target band (100-140 mg/dL). Second, measurement frequency was reduced, and only 2-hourly and 3-hourly interventions were used to reduce workload. These intervals allowed insulin infusions sufficient time to act so that the controller could more accurately identify insulin action. Finally, the SL2 protocol differed from the SL1 in that it did not specify any nutrition whatsoever. 
During the SL1 pilot trial, nutrition administration was generally left to the attending clinician who had to enter nutrition rates (and their changes) into the controller to account for the patient feeding. However, the SL1 protocol did recommended increased nutrition rates at low BG concentrations, to prevent unintended hypoglycemia. The SL2 protocol removed these recommendations, making the controller more simple and transparent. An improved glucose-insulin system model was also used (denoted ICING-2 [19]) and described in the Additional file 1. The four main steps of the new SL2 protocol are illustrated in Figure 1. They are described in detail below:

1. Previous and current BG measurements and clinical data (nutrition and insulin rates) are used to identify the current patient-specific model-based SI parameter value for the prior time interval [20]. This step accounts for inter-patient variability by adapting the model estimate of patient response to insulin [12].

2. All possible insulin rates are assessed, based on a minimum insulin rate $(0 \mathrm{U} / \mathrm{h})$, a $0.5 \mathrm{U} / \mathrm{h}$ insulin rate increment and a maximum insulin rate $\left(u_{\max }\right)$, of the current insulin rate $+2 \mathrm{U} / \mathrm{h}$ up to a maximum of $6 \mathrm{U} / \mathrm{h}$. Note that the insulin rate of $0.5 \mathrm{U} / \mathrm{h}$ is not considered due to its small size. Thus, possible insulin rates are $0,1,1.5,2 \ldots 6 \mathrm{U} / \mathrm{h}$. However, in two specific cases, no insulin is required. First, when the current BG level is lower than $90 \mathrm{mg} / \mathrm{dL}$; second, when the current $\mathrm{BG}$ value is more than $18 \mathrm{mg} / \mathrm{dL}$ below the $5^{\text {th }}$ percentile expected from the last controller intervention.

3. For each control interval ( 2 and 3 hours), the glycemic outcomes of all possible insulin interventions (defined in Step 2) are assessed. Only interventions that predicted a maximum risk of $5 \%$ or less for $\mathrm{BG}<90 \mathrm{mg} / \mathrm{dL}$, for safety from moderate $(<60 \mathrm{mg} / \mathrm{dL})$ or severe $(<40 \mathrm{mg} / \mathrm{dL})$ hypoglycemia [9], are considered feasible. More precisely, the assessment of each possible insulin intervention includes 3 phases:

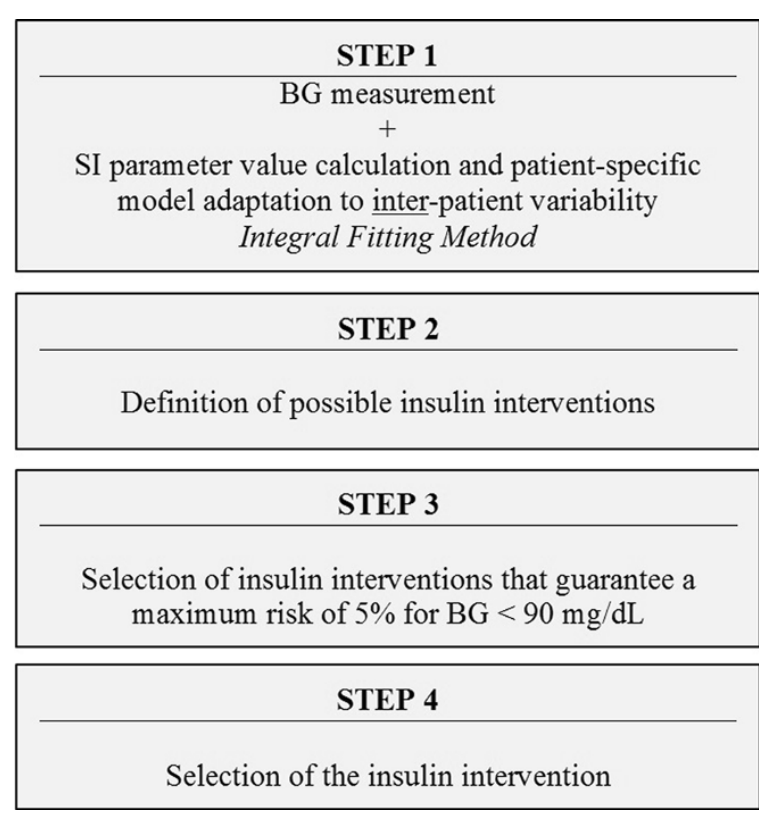

Figure 1 Steps of the STAR-Liege 2 protocol. 
a) The stochastic model [11] provides a distribution of possible SI parameter values for the next 2 (or 3) hours, based on the current SI value (identified in Step 1). This phase accounts for the intra-patient variability typically observed in critically ill patients.

b) The $5^{\text {th }}$ and the $50^{\text {th }}$ (median) percentile BG outcome predictions $\left(B G_{5 t h}\right.$ and $B G_{50 t h}$ respectively) are calculated using the insulin-glucose system model and using the $95^{\text {th }}$ and $50^{\text {th }}$ (median), respectively, percentile expected SI values obtained from Phase (a). The $B G_{5 t h}$ value illustrates the possible BG spread towards hypoglycemia due to intra-patient variability.

c) Hypoglycemic risk is assessed from the $5^{\text {th }}$ percentile BG value to restrict the forecasted risk of BG $<90 \mathrm{mg} / \mathrm{dL}$ to a $5 \%$ level. Thus $B G_{5 t h} \geq 90 \mathrm{mg} / \mathrm{dL}$ must be true for the insulin intervention to be feasible. For each time interval ( 2 and 3 hours), the goal is to find the insulin rates that put the 5th percentile BG closest to the lower bound of the target range (chosen as $100 \mathrm{mg} / \mathrm{dL}$ for this study) to maximize overlap of the outcome BG range with the desired target range. Additionally, $B G_{50 t h}<140 \mathrm{mg} / \mathrm{dL}$ is required for 3-hourly measurements, otherwise, only a 2-hour interval is offered.

4. The insulin intervention associated with the longest feasible time interval for the next BG measurement is selected to minimize workload.

Step 4 was changed for control of Patients 4 to 10 to allow nurses greater freedom. When 3-hourly measurements were available, three options were offered:

a) 2-hourly measurement, and insulin rate forecasted to achieve closest BG to target after 2 hours $\left(u_{1}\right)$

b) 3-hourly measurement and insulin rate forecasted to achieve closest BG to target after 3 hours $\left(u_{2}\right)$. Only patients $1-3$ received this option;

c) 3-hourly measurement and insulin rate using the lesser of the 2-hourly or 3-hourly insulin rates $\left(\min \left(u_{1}, u_{2}\right)\right)$.

By default, the controller would have chosen option (b), if available. The change to Step 4 enabled greater nursing flexibility and choice that better reflects STAR framework usage elsewhere [21] and made the system more user friendly.

The SL2 protocol was characterized by two glycemic bands (Figure 2): the $100-140 \mathrm{mg} / \mathrm{dL}$ target band and the range of glycemic outcomes due to insulin sensitivity variability (Step 3.b). The controller aimed to maximize the overlap between these two bands, subject to the $5^{\text {th }}$ percentile $B G \geq 90 \mathrm{mg} / \mathrm{dL}$.

\section{Stochastic model}

The stochastic model used with STAR described the hourly changes in insulin sensitivity to improve assessment of the patient's insulin response (Additional file 2). It was based on clinically observed insulin sensitivity variations in ICU populations [11]. The first pilot STAR-Liege trial (SL1) showed that post-operative cardiac surgery patients were significantly more variable in their insulin sensitivity (SI) than expected during the first post-operative hours [13]. In a final major difference from the first pilot trials in Liege, the stochastic model used in this study directly accounts for this variability by 

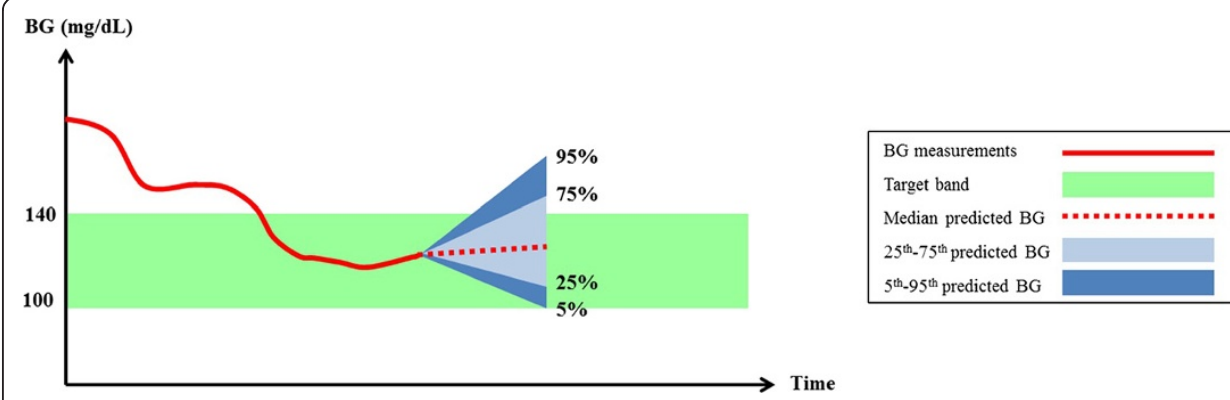

Figure 2 Overlapping of glycemic target band (green) and stochastic predicted range (blue) with $B G_{5 t h} \geq 90 \mathrm{mg} / \mathrm{dL}$.

using clinical data specific to cardiac-surgery patients and for the first days of stay. More precisely, it combined the data of cardiac surgery patients from the SPRINT study [5] with the data of all the patients of the Glucontrol study [22], to create a more cohort-specific stochastic model that was unique to this patient group and study.

\section{Clinical trial and patients}

The SL2 protocol was tested in November and December 2010 at the CHU in Liege, Belgium. Each pilot trial was 24 hours long. The clinical trial included 9 patients from the hospital's intensive care unit, 3 patients (Patients 2, 5 and 9) were in the first 48 hours post-surgery. Initially, patients were recruited if they had two consecutive blood glucose levels $>145 \mathrm{mg} / \mathrm{dL}$. In practice, clinicians also included highly glycemically variable patients (Patients 1, 2 and 5). The clinician stopped patient 2 after 7 hours due to the diagnosis of pancreatic disease. Table 1 shows the patient details and perpatient control information. The Ethics Committee of the Medical Faculty of the University of Liege (Liege, Belgium) granted approval for this trial and the audit, analysis and publication of these data.

For each patient, the trial started with a BG measurement made by nursing staff using a bedside glucometer (Accu-Check Inform, Roche Diagnostics, Mannheim, Germany) or a blood gas analyzer (RAPIDPoint 500 Systems, Siemens, Munich, Germany), depending on availability. This measurement was input to the computer and the controller calculated a new insulin infusion rate, which was then used by the nurse on the insulin infusion pumps. This clinical process is illustrated in Figure 3.

\section{Analyses}

Results are compared to the prior and subsequent 24 hours of hospital control to assess performance and safety versus typical hospital control. Results are also assessed compared to SL1 to determine if the goals of reduced workload with no compromise on performance or safety were achieved. In this study, glycemic variability refers to the spread of BG values across the cohort that could be illustrated by the slope of the BG cumulative density function $(\mathrm{CDF})$ or as the interquartile range.

\section{Results}

Clinical results are summarized in Tables 2, 3, and 4 and in Figures 4 and 5. A total of 91 measurements were taken over 194 hours, averaging one measurement every 
Table 1 Patient demographic and clinical data relevant to control

\begin{tabular}{|c|c|c|c|c|c|c|c|c|c|c|}
\hline & & Patient 1 & Patient 2 & Patient 3 & Patient 4 & Patient 5 & Patient 6 & Patient 7 & Patient 8 & Patient 9 \\
\hline \multirow{6}{*}{$\begin{array}{l}\text { General } \\
\text { information }\end{array}$} & Date of birth & $22 / 11 / 1938$ & 9/09/1938 & 8/12/1959 & $11 / 07 / 1922$ & $11 / 12 / 1938$ & 9/09/1938 & $5 / 12 / 1944$ & 19/05/1951 & 7/01/1939 \\
\hline & Sex & $\mathrm{F}$ & $\mathrm{F}$ & M & M & M & $\mathrm{F}$ & M & $\mathrm{F}$ & $\mathrm{F}$ \\
\hline & Diagnosis & Gastro & Cardio & Trauma & Neurological & Respiratory & $\begin{array}{l}\text { Cardio (then } \\
\text { pneumonic) }\end{array}$ & Cardio & Cardio & Cardio \\
\hline & Diabetic & No & No & No & No & Unknown & No & Yes & Yes & Yes \\
\hline & $\begin{array}{l}\text { Post-surgical days } \\
\text { in ICU }\end{array}$ & 20 & 0 & 4 & 3 & 2 & 8 & 22 & 4 & 2 \\
\hline & Trial date & 15/12/2010 & $22 / 11 / 2010$ & $22 / 11 / 2010$ & $24 / 11 / 2010$ & 24/11/2010 & $30 / 11 / 2010$ & $30 / 11 / 2010$ & $30 / 11 / 2010$ & $15 / 12 / 2010$ \\
\hline \multirow[t]{6}{*}{ Control details } & Start time & 17:00 & $13: 10$ & $16: 00$ & 14:00 & $18: 00$ & $20: 00$ & $17: 00$ & 21:00 & 14:00 \\
\hline & Initial BG (mg/dL) & 118 & 159 & 164 & 168 & 223 & 125 & 138 & 127 & 155 \\
\hline & $\begin{array}{l}\text { Number of nurse } \\
\text { interventions that } \\
\text { differed from the } \\
\text { protocol } \\
\text { recommendations }\end{array}$ & 0 & $\begin{array}{l}1 \text { intervention } \\
\text { of } 4 \\
\text { interventions }\end{array}$ & $\begin{array}{l}3 \text { interventions } \\
\text { of } 9 \\
\text { interventions }\end{array}$ & $\begin{array}{l}7 \text { interventions } \\
\text { of } 12 \\
\text { interventions }\end{array}$ & $\begin{array}{l}1 \text { intervention } \\
\text { of } 11 \\
\text { interventions }\end{array}$ & 0 & $\begin{array}{c}2 \text { interventions } \\
\text { of } 11 \\
\text { interventions }\end{array}$ & $\begin{array}{l}7 \text { interventions } \\
\text { of } 11 \\
\text { interventions }\end{array}$ & $\begin{array}{l}2 \text { interventions } \\
\text { of } 11 \\
\text { interventions }\end{array}$ \\
\hline & Meals & / & / & / & / & / & / & / & $\begin{array}{c}\text { 1/12/2011 (9:45): } \\
\text { bread (120 mL/h } \\
\text { during } 15 \mathrm{~min})\end{array}$ & $\begin{array}{l}\text { 15/12/2010 (12:00): } \\
\text { soup (30 mL/h } \\
\text { during } 15 \mathrm{~min})\end{array}$ \\
\hline & & & & & & & & & $\begin{array}{l}\text { 1/12/2011 } \\
\text { (12:00): vegetables } \\
\text { (not taken into } \\
\text { account) }\end{array}$ & $\begin{array}{c}\text { 15/12/2010 (19:00) } \\
\text { bread, cheese, } \\
\text { carrots ( } 90 \mathrm{~mL} / \mathrm{h} \\
\text { during } 15 \mathrm{~min} \\
\text { maybe } \\
\text { underestimated) }\end{array}$ \\
\hline & & & & & & & & & $\begin{array}{c}\text { 1/12/2011 (18:30): } \\
\text { bread (90 mL/h } \\
\text { during } 15 \mathrm{~min})\end{array}$ & $\begin{array}{c}\text { 16/12/2010 } \\
\text { (10:00): bread, } \\
\text { orange, coffee } \\
(90 \mathrm{~mL} / \mathrm{h} \\
\text { during } 15 \mathrm{~min})\end{array}$ \\
\hline
\end{tabular}


Table 1 Patient demographic and clinical data relevant to control (Continued)

16/12/2010 (12:00):

soup, vegetables,

meat $(120 \mathrm{~mL} / \mathrm{h}$

meat $(120 \mathrm{~mL} / \mathrm{h}$
during $15 \mathrm{~min})$

Additional drugs

/

Vomiting?

No

Notes

Vasopressor Hydrocortisone (Noradrenaline) 


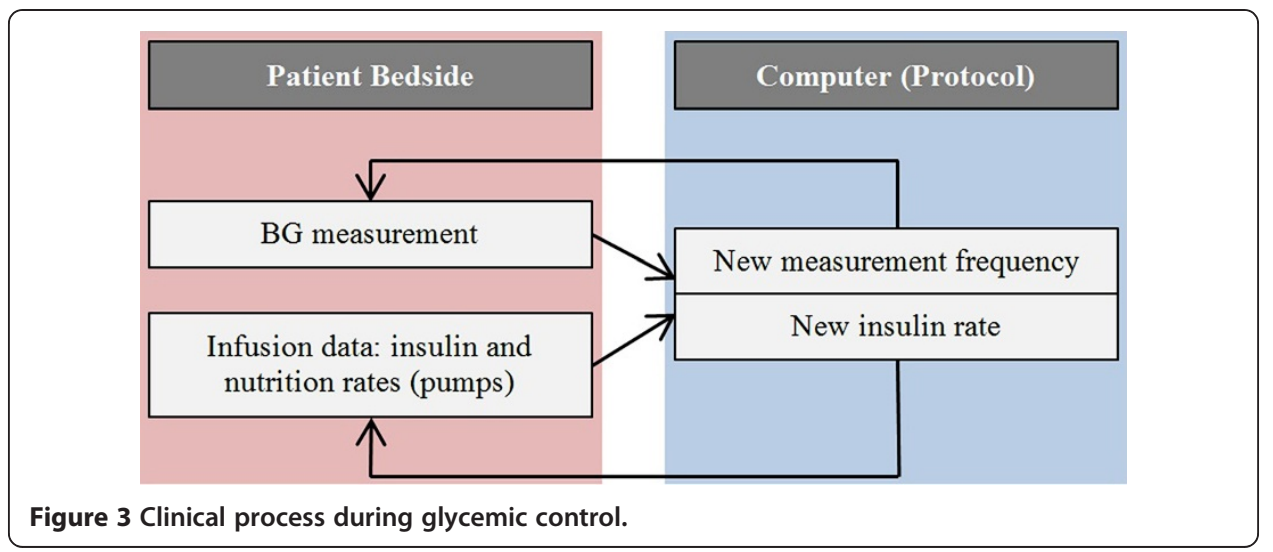

2.1 hours ( 11/day). BG levels were relatively tightly distributed, as evidenced by the interquartile range (IQR) range of $33.6 \mathrm{mg} / \mathrm{dL}\left(25^{\text {th }}-75^{\text {th }}\right.$ percentile: $\left.117.2-150.8 \mathrm{mg} / \mathrm{dL}\right)$ in Table 2 for the cohort and by the IQR for per-patient median values across patients in Table 3. The percentage of BG measurements within the 100-140 mg/dL target band was $54.9 \%$ indicating that the control was tight in this band, as illustrated by the steep slope of BG cumulative density function (CDF) for the whole cohort in Figure 4. A total of $40.7 \%$ of the BG measurements were $\geq 140 \mathrm{mg} / \mathrm{dL}$ primarily due to high initial BG values and short 24-hour trials. The remaining $4.4 \%$ of measurements (4 measurements) had $\mathrm{BG}<100 \mathrm{mg} / \mathrm{dL}$. There were no severe hypoglycemic events $(\mathrm{BG}<40 \mathrm{mg} / \mathrm{dL})$ and the minimum recorded BG was $70 \mathrm{mg} / \mathrm{dL}$ (Patient 7). Hence, while STAR forecasted a maximum risk of $5 \%$ for $B G<90 \mathrm{mg} / \mathrm{dL}$ by design, clinical results show only $3.3 \%$.

Table 2 Whole cohort glycemic control results

\begin{tabular}{|c|c|c|c|c|c|}
\hline & \multicolumn{3}{|c|}{ SL2 clinical data } & \multirow{2}{*}{$\begin{array}{c}\begin{array}{c}\text { SL1 clinical } \\
\text { data }\end{array} \\
\text { Pilot trial }(+)\end{array}$} & \multirow{2}{*}{$\begin{array}{c}\text { p-value } \\
\text { SL1 vs. } \\
\text { SL2 }\end{array}$} \\
\hline & Pre 24 hour & Pilot trial (+) & Post 24 hour & & \\
\hline Number of patients: & 9 & 9 & 9 & 9 & / \\
\hline Total hours: & / & $194 \mathrm{~h}$ & / & $215 \mathrm{~h}$ & / \\
\hline Number of BG measurements: & 46 & 91 & 44 & 205 & / \\
\hline BG median $[\mathrm{IQR}](\mathrm{mg} / \mathrm{dL})$ : & $\begin{array}{c}155.5 \\
{[124.0-171.0]}\end{array}$ & $\begin{array}{c}134.0 \\
{[117.2-150.8]}\end{array}$ & $\begin{array}{c}136.5 \\
{[115.0-159.5]}\end{array}$ & $\begin{array}{c}136.0 \\
{[122.5-158.0]}\end{array}$ & $0.27\left(^{*}\right)$ \\
\hline$\%$ BG within $80-100 \mathrm{mg} / \mathrm{dL}$ & 8.7 & 3.3 & 6.82 & 3.4 & 1.00 \\
\hline$\%$ BG within $100-140 \mathrm{mg} / \mathrm{dL}$ & 10.9 & 54.9 & 43.18 & 50.7 & 0.53 \\
\hline$\%$ BG within $140-180 \mathrm{mg} / \mathrm{dL}$ & 50.0 & 33.0 & 36.36 & 37.1 & 0.51 \\
\hline$\% \mathrm{BG} \geq 180 \mathrm{mg} / \mathrm{dL}$ & 19.6 & 7.7 & 9.09 & 8.3 & 1.00 \\
\hline$\% \mathrm{BG}<90 \mathrm{mg} / \mathrm{dL}$ & 19.6 & 3.3 & 11.4 & 2.0 & 0.44 \\
\hline$\% \mathrm{BG}<80 \mathrm{mg} / \mathrm{dL}$ & 10.9 & 1.1 & 4.55 & 0.5 & 0.52 \\
\hline$\% \mathrm{BG}<40 \mathrm{mg} / \mathrm{dL}$ & 0.0 & 0.0 & 0.0 & 0.0 & 1.00 \\
\hline Number of patients $<40 \mathrm{mg} / \mathrm{dL}$ & 0 & 0 & 0 & 0 & / \\
\hline Median insulin rate [IQR] (U/h): & / & $2.0[1.0-2.5]$ & / & $1.5[0.5-3.4]$ & $\left.0.922^{*}\right)$ \\
\hline Median glucose rate [IQR] (g/h): & / & $0.0[0.0-5.4]$ & / & $7.4[2.0-11.2]$ & $0.00\left(^{*}\right)$ \\
\hline
\end{tabular}

The 24-hour pre-trial, during pilot trial and post-trial glycemic data are summarized for SL2 clinical trial. Whole cohort results for SL1 and SL2 pilot trials (+) are compared and p-values were calculated using the Fisher exact test (2-tails) excepted for distributions $\left(^{*}\right)$ where a Wilcoxon rank sum test for equal medians was used. 
Table 3 Per-patient glycemic control results during SL2 pilot trial

\begin{tabular}{lc}
\hline Initial BG (mg/dL): & $155.0[126.5-165.0]$ \\
Hours of control: & $23.0[23.0-24.0]$ \\
Number of BG measurements: & $11.0[10.5-11.0]$ \\
BG median (mg/dL) & $137.0[120.3-142.4]$ \\
Median\% BG within 80-100 mg/dL: & $0.0[0.0-9.1]$ \\
Median\% BG within 100-140 mg/dL: & $54.5[43.2-68.2]$ \\
Median\% BG within 140-180 mg/dL: & $36.4[18.2-46.6]$ \\
Median\% BG $\geq 180 \mathrm{mg} / \mathrm{dL}:$ & $0.0[0.0-19.9]$ \\
Time to < $125 \mathrm{mg} / \mathrm{dL}(\mathrm{h}):$ & $6.6[1.9-9.0]$ \\
\% patients to < $125 \mathrm{mg} / \mathrm{dL}:$ & 88.9 \\
Time to < $140 \mathrm{mg} / \mathrm{dL}(\mathrm{h}):$ & $1.8[0.0-2.6]$ \\
\% patients to < $140 \mathrm{mg} / \mathrm{dL}:$ & 100 \\
Median insulin rate $(\mathrm{U} / \mathrm{h}):$ & $1.4[0.2-2.6]$ \\
Max insulin rate $(\mathrm{U} / \mathrm{h}):$ & $3.0[2.9-4.0]$ \\
Median glucose rate $(\mathrm{g} / \mathrm{h}):$ & $0.0[0.0-4.7]$ \\
\hline
\end{tabular}

Statistics are presented as median [IQR] when it's appropriated.

For context, BG results are compared to 24-hour pre-trial and 24-hour post-trial BG results of the same nine patients so that each patient acts as their own control. Table 2 shows that SL2 provided better glycemic control compared to the pre-trial period, with $54.9 \%$ of BG in the clinically desired band (100-140 mg/dL), instead of $10.9 \%$. This improved control was associated with reduced high BG levels (from 19.6\% to $7.7 \%$ of $\mathrm{BG} \geq 180 \mathrm{mg} / \mathrm{dL}$ ) and significantly reduced low BG levels (from $10.9 \%$ to $1.1 \%$ of BG $<80 \mathrm{mg} / \mathrm{dL}$ ). SL2 did not shift BG levels towards a desired glycemic band, but instead gathered BG levels in a range, as illustrated by the steeper slopes of the BG CDF in Figure 5. The 24 hours following STAR were similar, but more variable, as shown in Figure 5. Overall, STAR successfully reduced BG levels and variability compared to hospital control, while decreasing low BG levels and thus increasing safety.

Table 5 shows details about interventions when nurse interventions differed from protocol recommendations, for insulin rates and/or measurement frequency. Surprisingly, when a 3-hourly option was available, nurses did not always choose this option (2-hourly intervention chosen 11 of 16 cases, 69\%, Table 5). Figure 4 shows that no insulin was given in $18 \%$ of control interventions, and that insulin rates varied over the full range allowed. Only $5 \%$ of insulin rates were higher than $4 \mathrm{U} / \mathrm{h}$, and only Patient 5 received the maximum allowable insulin rate of $6 \mathrm{U} / \mathrm{h}$ during the 24-hour trial (Table 4). Nurses overrode 23 (12\%) of the 194 interventions recommended by the protocol: 8 (35\%) increased insulin rates and 15 (65\%) decreased insulin rates (Table 5).

As mentioned, nutrition input was left to the attending clinician. Approximately $40 \%$ of dextrose rates were equal to zero, as five patients received no exogenous dextrose inputs (Patients 3, 4, 6 and 10, Table 4). Clinical results show that the patients were each fed very differently.

Table 2 and Figure 4 show that SL2 achieved somewhat tighter, equally safe control compared to SL1. BG levels were similarly distributed ( $p>0.05$ ), while the number of measurements was reduced by $55.6 \%(\mathrm{p}<0.05)$. SL2 had slightly lower insulin rates due to the significantly lower exogenous glucose administration rates $(\mathrm{p}<0.01)$. 
Table 4 Individual patient results during SL2 pilot trial

\begin{tabular}{|c|c|c|c|c|c|c|c|c|c|c|c|c|c|c|c|}
\hline Patient & $\begin{array}{l}\text { Total } \\
\text { hours }\end{array}$ & $\begin{array}{c}\text { Num. } \\
\text { measurements }\end{array}$ & $\begin{array}{c}\text { Initial } \\
\text { BG } \\
\text { (mg/dL): }\end{array}$ & $\begin{array}{c}\text { BG } \\
\text { median } \\
{[\mathrm{IQR}]} \\
(\mathrm{mg} / \mathrm{dL}):\end{array}$ & $\begin{array}{c}\% \text { BG } \\
\text { within 80- } \\
100 \mathrm{mg} / \mathrm{dL}\end{array}$ & $\begin{array}{c}\% \text { BG within } \\
100- \\
140 \mathrm{mg} / \mathrm{dL}\end{array}$ & $\begin{array}{c}\text { \% BG within } \\
140- \\
180 \mathrm{mg} / \mathrm{dL}\end{array}$ & $\begin{array}{c}\% \mathrm{BG} \geq \\
180 \mathrm{mg} / \\
\mathrm{dL}\end{array}$ & $\begin{array}{c}\% \mathrm{BG}< \\
80 \mathrm{mg} / \\
\mathrm{dL}\end{array}$ & $\begin{array}{c}\% \mathrm{BG}< \\
72 \mathrm{mg} / \\
\mathrm{dL}\end{array}$ & $\begin{array}{c}\% \mathrm{BG}< \\
40 \mathrm{mg} / \\
\mathrm{dL}\end{array}$ & $\begin{array}{c}\text { Min BG } \\
\text { level } \\
\text { (mg/dL) }\end{array}$ & $\begin{array}{l}\text { Median insulin } \\
\text { rate [IQR] } \\
\text { (U/h): }\end{array}$ & $\begin{array}{c}\text { Max } \\
\text { insulin rate } \\
(\mathrm{U} / \mathrm{h}):\end{array}$ & $\begin{array}{l}\text { Median } \\
\text { glucose rate } \\
{[\text { [IQR] }(g / h):}\end{array}$ \\
\hline 1 & 23 & 11 & 118 & $\begin{array}{c}118.0 \\
{[112.8-135.8]}\end{array}$ & 9.1 & 72.7 & 18.2 & 0 & 0 & 0 & 0 & 80 & $0.0[0.0-1.0]$ & 2.0 & $0.0[0.0-0.0]$ \\
\hline 2 & 7 & 4 & 159 & $\begin{array}{c}163.5 \\
{[142.5-204.0]}\end{array}$ & 0.0 & 25.0 & 50.0 & 25 & 0 & 0 & 0 & 126 & $0.3[0.0-2.1]$ & 4.0 & $4.5[0.3-4.5]$ \\
\hline 3 & 23 & 9 & 164 & $\begin{array}{c}137.0 \\
{[131.0-148.0]}\end{array}$ & 0.0 & 66.7 & 33.3 & 0 & 0 & 0 & 0 & 122 & $2.0[2.0-2.5]$ & 3.0 & $0.0[0.0-0.0]$ \\
\hline 4 & 24 & 12 & 168 & $\begin{array}{c}140.5 \\
{[130.5-146.0]}\end{array}$ & 0.0 & 50.0 & 50.0 & 0 & 0 & 0 & 0 & 109 & $2.7[2.5-3.5]$ & 3.5 & $0.0[0.0-0.0]$ \\
\hline 5 & 23 & 11 & 223 & $\begin{array}{c}148.0 \\
{[133.8-171.0]}\end{array}$ & 0.0 & 36.4 & 45.5 & 18.2 & 0 & 0 & 0 & 110 & $4.0[2.5-4.5]$ & 6.0 & $5.6[5.6-8.5]$ \\
\hline 6 & 24 & 11 & 125 & $\begin{array}{c}118.0 \\
{[107.0-125.8]}\end{array}$ & 9.1 & 72.7 & 18.2 & 0 & 0 & 0 & 0 & 82 & $0.0[0.0-1.0]$ & 3.0 & $0.0[0.0-0.0]$ \\
\hline 7 & 23 & 11 & 138 & $\begin{array}{c}138.0 \\
{[120.5-145.3]}\end{array}$ & 0.0 & 54.5 & 36.4 & 0 & 9.1 & 9.1 & 0 & 70 & $2.5[1.7-3.0]$ & 4.0 & $5.4[5.4-5.4]$ \\
\hline 8 & 23 & 11 & 127 & $\begin{array}{c}134.0 \\
{[103.8-169.0]}\end{array}$ & 9.1 & 45.5 & 36.4 & 9.1 & 0 & 0 & 0 & 97 & $1.0[0.5-1.5]$ & 2.5 & $0.0[0.0-0.0]$ \\
\hline 9 & 24 & 11 & 155 & $\begin{array}{c}121.0 \\
{[109.0-176.8]}\end{array}$ & 0.0 & 54.5 & 18.2 & 27.3 & 0 & 0 & 0 & 103 & $1.4[1.0-1.9]$ & 3.0 & $2.0[2.0-2.0]$ \\
\hline
\end{tabular}



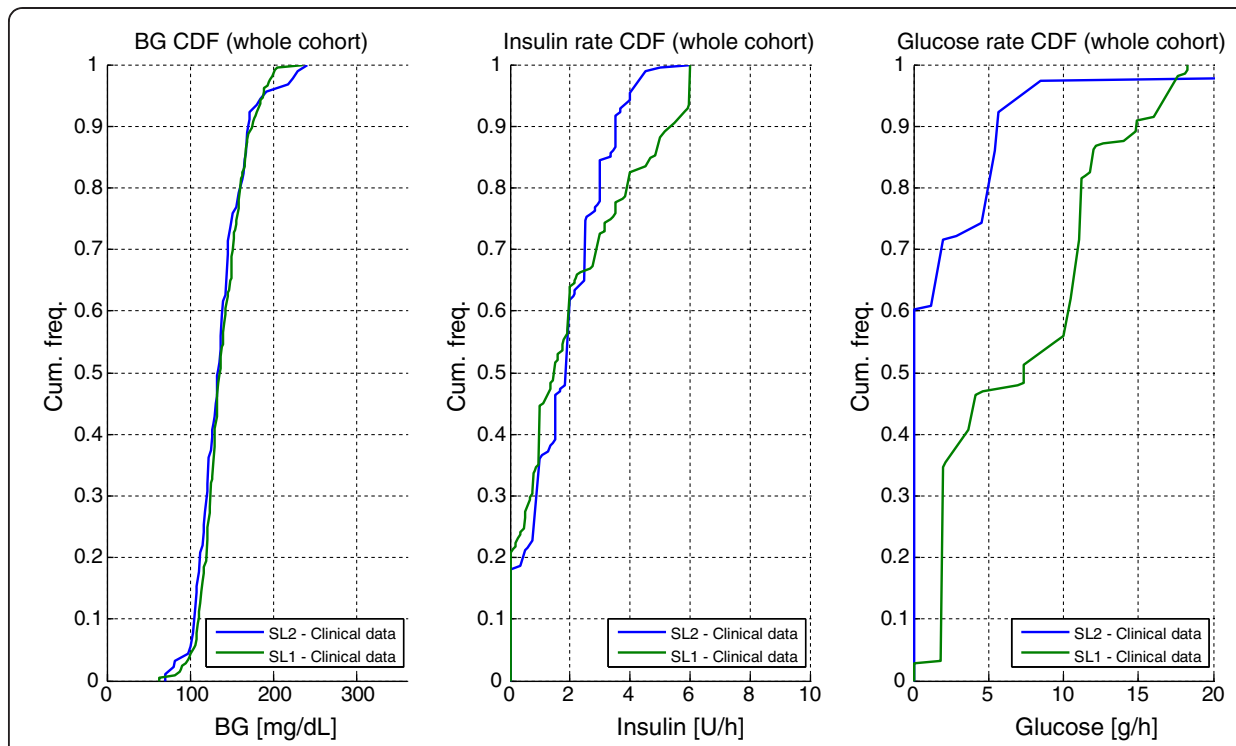

Figure 4 Whole cohort cumulative density function (CDF) for BG (left panel), insulin rates (middle panel) and exogenous glucose rate (right panel). Results of the STAR-Liege 1 (SL1, green) and STARLiege 2 (SL2, blue) clinical trials are illustrated.

\section{Discussion}

The SL2 protocol was primarily designed to reduce nurse workload, while maintaining safety and control. Three main changes were made. First, while SL1 was characterized by a specific glycemic target of $125 \mathrm{mg} / \mathrm{dL}$, SL2 used a target-to-range approach (target band: $100-140 \mathrm{mg} / \mathrm{dL}$ ). Second, measurement frequency was reduced as only 2-hourly and 3-hourly interventions were used, instead of the 1- and 2- hourly interventions during the first trial. Third, the SL2 protocol had fewer rules (for example, it did not adjust nutrition rates), which made the protocol more simple and transparent, and its application faster. Additionally, the controller used an improved model of the glucose-

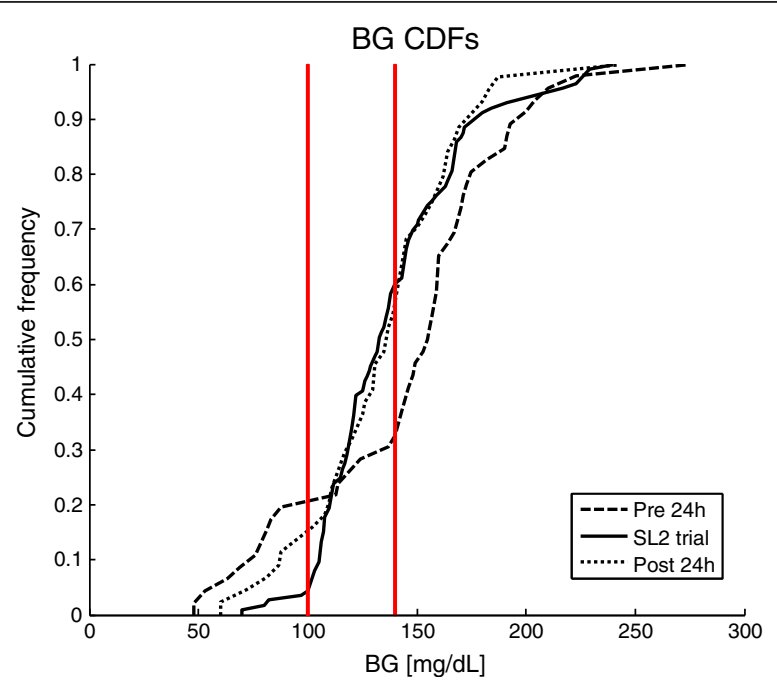

Figure 5 Cumulative density function (CDF) for BG levels for 24-hour pre-trial, during trial and posttrial for SL2 pilot trial. Target band bounds (100 mg/dL and $140 \mathrm{mg} / \mathrm{dL}$ ) are highlighted. 
Table 5 Details where nurses overrode STAR recommendations during the SL2 pilot trial

\begin{tabular}{|c|c|c|c|c|}
\hline & & Protocol recommendations & Nurses interventions & \\
\hline Patient 2 & Intervention 1 & $3.5 \mathrm{U} / \mathrm{h}$ for $2 \mathrm{~h}$ & $1.5 \mathrm{U} / \mathrm{h}$ for $1 \mathrm{~h}$ & \\
\hline \multirow[t]{3}{*}{ Patient 3} & Intervention 1 & $6 \mathrm{U} / \mathrm{h}$ for $3 \mathrm{~h}$ & $3 \mathrm{U} / \mathrm{h}$ for $2 \mathrm{~h}$ & - \\
\hline & Intervention 2 & $3.5 \mathrm{U} / \mathrm{h}$ for $3 \mathrm{~h}$ & $2.5 \mathrm{U} / \mathrm{h}$ for $3 \mathrm{~h}$ & * \\
\hline & Intervention 3 & $3.5 \mathrm{U} / \mathrm{h}$ for $3 \mathrm{~h}$ & $3 \mathrm{U} / \mathrm{h}$ for $3 \mathrm{~h}$ & * \\
\hline \multirow[t]{7}{*}{ Patient 4} & Intervention 1 & $4.5 \mathrm{U} / \mathrm{h}$ for $2 \mathrm{~h}$ & $3.5 \mathrm{U} / \mathrm{h}$ for $2 \mathrm{~h}$ & \\
\hline & Intervention 2 & $5.5 \mathrm{U} / \mathrm{h}$ for $3 \mathrm{~h}$ & $3.5 \mathrm{U} / \mathrm{h}$ for $2 \mathrm{~h}$ & - \\
\hline & Intervention 3 & $4 \mathrm{U} / \mathrm{h}$ for $2 \mathrm{~h}$ & $3.5 \mathrm{U} / \mathrm{h}$ for $2 \mathrm{~h}$ & \\
\hline & Intervention 4 & $1 \mathrm{U} / \mathrm{h}$ for $3 \mathrm{~h}$ or no insulin for $2 \mathrm{~h}$ & $2 \mathrm{U} / \mathrm{h}$ for $2 \mathrm{~h}$ & - \\
\hline & Intervention 5 & $4.5 \mathrm{U} / \mathrm{h}$ for $2 \mathrm{~h}$ or $4 \mathrm{U} / \mathrm{h}$ for $3 \mathrm{~h}$ & $3 \mathrm{U} / \mathrm{h}$ for $2 \mathrm{~h}$ & - \\
\hline & Intervention 6 & $2 \mathrm{U} / \mathrm{h}$ for $2 \mathrm{~h}$ or $3 \mathrm{~h}$ or $3 \mathrm{U} / \mathrm{h}$ for $3 \mathrm{~h}$ & $2.5 \mathrm{U} / \mathrm{h}$ for $2 \mathrm{~h}$ & _ \\
\hline & Intervention 7 & $4 \mathrm{U} / \mathrm{h}$ for $2 \mathrm{~h}$ & $3.5 \mathrm{U} / \mathrm{h}$ for $2 \mathrm{~h}$ & \\
\hline Patient 5 & Intervention 1 & $5.5 \mathrm{U} / \mathrm{h}$ for $2 \mathrm{~h}$ & $4.5 \mathrm{U} / \mathrm{h}$ for $2 \mathrm{~h}$ & \\
\hline \multirow[t]{2}{*}{ Patient 7} & Intervention 1 & $1 \mathrm{U} / \mathrm{h}$ for $2 \mathrm{~h}$ or $3 \mathrm{~h}$ or $1.5 \mathrm{U} / \mathrm{h}$ for $3 \mathrm{~h}$ & $1.5 \mathrm{U} / \mathrm{h}$ for $2 \mathrm{~h}$ & - \\
\hline & Intervention 2 & No insulin for $2 \mathrm{~h}$ or $3 \mathrm{~h}$ & $1 \mathrm{U} / \mathrm{h}$ for $2 \mathrm{~h}$ & - \\
\hline \multirow[t]{7}{*}{ Patient 8} & Intervention 1 & $1.5 \mathrm{U} / \mathrm{h}$ for $2 \mathrm{~h}$ or $3 \mathrm{~h}$ & $1 \mathrm{U} / \mathrm{h}$ for $2 \mathrm{~h}$ & - \\
\hline & Intervention 2 & $2 \mathrm{U} / \mathrm{h}$ for $2 \mathrm{~h}$ & $1 \mathrm{U} / \mathrm{h}$ for $2 \mathrm{~h}$ & \\
\hline & Intervention 3 & $2 \mathrm{U} / \mathrm{h}$ for $3 \mathrm{~h}$ or $3 \mathrm{U} / \mathrm{h}$ for $2 \mathrm{~h}$ & $1.5 \mathrm{U} / \mathrm{h}$ for $2 \mathrm{~h}$ & - \\
\hline & Intervention 4 & No insulin for $2 \mathrm{~h}$ or $3 \mathrm{~h}$ & $0.5 \mathrm{U} / \mathrm{H}$ for $2 \mathrm{~h}$ & - \\
\hline & Intervention 5 & No insulin for $3 \mathrm{~h}$ & $0.5 \mathrm{U} / \mathrm{H}$ for $3 \mathrm{~h}$ & * \\
\hline & Intervention 6 & $3.5 \mathrm{U} / \mathrm{h}$ for $2 \mathrm{~h}$ or $3 \mathrm{~h}$ & $2.5 \mathrm{U} / \mathrm{h}$ for $2 \mathrm{~h}$ & - \\
\hline & Intervention 7 & $1.5 \mathrm{U} / \mathrm{h}$ for $3 \mathrm{~h}$ & $2 \mathrm{U} / \mathrm{h}$ for $3 \mathrm{~h}$ & * \\
\hline \multirow[t]{2}{*}{ Patient 9} & Intervention 1 & No insulin for $3 \mathrm{~h}$ & $1 \mathrm{U} / \mathrm{h}$ for $3 \mathrm{~h}$ & * \\
\hline & Intervention 2 & No insulin for $2 \mathrm{~h}$ & $0.5 \mathrm{U} / \mathrm{H}$ for $2 \mathrm{~h}$ & \\
\hline
\end{tabular}

Nurses overrode 23 of 91 interventions. (-): Interventions where nurses chose 2-hourly intervention when 3-hourly intervention is available; $\left(^{*}\right)$ interventions where nurses chose 3-hourly intervention when 3-hourly intervention is available.

insulin system [19] and a cohort-specific stochastic model to account for a more variable cardiovascular cohort [13].

Nurse workload was significantly reduced with the SL2 protocol (2.1 hours between measurements vs. 1.1 for SL1, $\mathrm{p}<0.01$ ). Table 5 shows that nurses sometimes choose 2-hourly interventions (31\% of time) when a 3-hourly option was available. This result indicates that measurement frequency could have been further reduced if nurses chose 3-hourly interventions when available. Hence, nurse workload could have been further reduced.

Nurses overrode insulin rates more often during the SL2 clinical trial than during the SL1 clinical trial. This difference can be explained by some "lack of trust" in the recommendations, especially as the time interval was longer. Nurses were hesitant to administer more than $3 \mathrm{U} / \mathrm{h}$, and were quite resistant to insulin rate changes (Table 5). However, $35 \%$ of override changes increased insulin over recommendations. Table 2 and Figure 5 show that hospital control was less effective and more variable than STAR, so this non-compliance may not have improved control.

SL2 explicitly defined a maximum hypoglycemic risk of $5 \%$ of $B G<90 \mathrm{mg} / \mathrm{dL}$. In contrast, SL1 used a maximum $5 \%$ risk of BG $<72 \mathrm{mg} / \mathrm{dL}$ [18]. During the SL1 trial, there were $2.0 \%$ of $B G<90 \mathrm{mg} / \mathrm{dL}$, representing 4 of 205 BG measurements. During the SL2 trial, there were 3 of $91 \mathrm{BG}<90 \mathrm{mg} / \mathrm{dL}$ (3.3\%). This percentage (and number) 
of BG $<90 \mathrm{mg} / \mathrm{dL}$ are acceptable as it is less than the desired maximum of $5 \%$ ( 4-5 BG measurements over 91). Despite less frequent measurement and intervention, safety was still ensured, and matched design levels.

The relatively short length of each trial does not allow long-term statistics on control. However, a median 1.8 hours to $B G<140 \mathrm{mg} / \mathrm{dL}$ indicates total trial length was sufficient to test safety and efficacy compared to SL1. The results justify longer trials for 48 or more hours.

A main difference between the SL1 and SL2 results was the reduced intervention rate, which can increase BG variability in patients whose condition changes rapidly. However, the longer intervals allowed the effect of changes in insulin infusion rate to be more clearly observed and identified, compared to bolus administration in other uses [21] which act more quickly and can thus be more rapidly identified. However, these results indicate no increase in variability or risk as a result.

Some situations are still not automatically managed by STAR. In particular, small meals may be given (Patients 8 and 9, Table 1) which are difficult to estimate. The added estimated exogenous glucose content was included in control. However, incomplete consumption and estimated exogenous glucose content adds uncertainty, although STAR appeared to manage this issue as well as, or better, than normal hospital control. Future efforts need to include this aspect more explicitly.

Finally, this clinical trial includes only 9 subjects. Longer trials over more patients would provide greater certainty to the results. However, it is clear that the goals of reducing workload without compromising safety or performance were met. Equally, it is clear that STAR was better than the normal hospital protocol. The STAR protocol gathered BG levels around the desired glycemic band, reduced high BG levels and improved safety by significantly reducing low BG levels. STAR also positively impacted on 24-hour post-trial glycemic results. Hence, STAR also helped stabilizing patient condition and helped further patient management.

\section{Conclusion}

The main objective for these second clinical trials was to reduce clinical workload, while maintaining control quality and safety, using a target-to-range approach. Results show that clinical workload was reduced by over a factor of 2 , while safety was maintained with less frequent measurement and intervention compared to prior clinical trial. The results presented thus show that safe, effective glycemic control can be achieved for a highly variable cohort with significantly reduced workload using a model-based method, where several clinical studies on similar cardiovascular cohorts have had excessive hypoglycemia. Moreover, STAR was shown to be safer and tighter than the existing hospital control.

\section{Additional files}

Additional file 1: This file provides the description of the glucose-insulin model.

Additional file 2: This file provides the description of the stochastic model. 


\section{Competing interests}

The authors declare that they have no competing interests.

\section{Authors' contribution}

ALC developed the SL2 model-based protocol. SP and KTM conducted the trial and made the acquisition of data during the clinical trials. All authors were involved in the analysis and interpretation of data. The manuscript was originally drafted by SP, and JGC, but all authors made contributions through the entire process, including reading and final approval of this manuscript.

\section{Authors' information}

MSc, Cardiovascular Research Centre, Institut de Physique, Université de Liege, Institut de Physics, Allée du 6 Août, 17 (Bât B5), B4000 Liege, Liege, Belgium.

PhD, Cardiovascular Research Centre, Institut de Physique, Université de Liege, Institut de Physics, Allée du 6 Août, 17 (Bât B5), B4000 Liege, Liege, Belgium.

PhD, Department of Mechanical Engineering, Centre for Bio-Engineering, University of Canterbury, Christchurch, Private Bag 4800, 8054, New Zealand.

MSc, Department of Mechanical Engineering, Centre for Bio-Engineering, University of Canterbury, Christchurch, Private Bag 4800, 8054, New Zealand.

PhD, Department of Mechanical Engineering, Centre for Bio-Engineering, University of Canterbury, Christchurch, Private Bag 4800, 8054, New Zealand.

MD, PhD, Department of Intensive Care, Erasme University Hospital, 808 route de Lennik, B1070 Brussels, Belgium. MB, ChB, Department of Intensive Care, Christchurch Hospital, Christchurch, 8054, New Zealand

MD, PhD, Department of Intensive Care, CHU, Liege, Belgium.

\section{Acknowledgements}

Financial Support:

- Fonds National de la Recherche Scientifique (F.R.S.-FNRS, Belgium).

- NZ Foundation for Research Science and Technology (FRST).

- Department of Mechanical Engineering, Scholarship Grant, University of Canterbury, Christchurch, New Zealand.

\section{Author details}

${ }^{1}$ Dept of Mechanical Eng, Centre for Bio-Engineering, University of Canterbury, Christchurch, Private Bag 4800, 8054, New Zealand. ${ }^{2}$ Cardiovascular Research Centre, Institut de Physique, Université de Liege, Institut de Physics, Allée du 6 Août, 17 (Bât B5), Liege B4000 Liege, Liege, Belgium. ${ }^{3}$ Dept of Intensive Care, Erasme University Hospital, 808 route de Lennik, Brussels B1070, Belgium. ${ }^{4}$ University of Otago Christchurch, School of Medicine, Christchurch 8054, New Zealand. ${ }^{5}$ Dept of Intensive Care, Christchurch Hospital, Christchurch 8054, New Zealand. ${ }^{6}$ Dept of Intensive Care, CHU, Liege, Belgium.

Received: 18 June 2012 Accepted: 27 July 2012

Published: 23 August 2012

\section{References}

1. Capes SE, Hunt D, Malmberg K, Gerstein HC: Stress hyperglycaemia and increased risk of death after myocardial infarction in patients with and without diabetes: a systematic overview. Lancet 2000, 355(9206):773-778

2. Egi M, Bellomo R, Stachowski E, French CJ, Hart G: Variability of blood glucose concentration and short-term mortality in critically ill patients. Anesthesiology 2006, 105(2):244-252.

3. Egi M, Bellomo R, Stachowski E, French CJ, Hart GK, Taori G, Hegarty C, Bailey M: Hypoglycemia and outcome in critically ill patients. Mayo Clin Proc 2010, 85(3):217-224.

4. Krinsley JS: Association between hyperglycemia and increased hospital mortality in a heterogeneous population of critically ill patients. Mayo Clin Proc 2003, 78(12):1471-1478.

5. Chase JG, Shaw G, Le Compte A, Lonergan T, Willacy M, Wong XW, Lin J, Lotz T, Lee D, Hann C: Implementation and evaluation of the SPRINT protocol for tight glycaemic control in critically ill patients: a clinical practice change. Crit Care 2008, 12(2):R49.

6. Krinsley JS: Effect of an intensive glucose management protocol on the mortality of critically ill adult patients. Mayo Clin Proc 2004, 79(8):992-1000

7. Van den Berghe G, Wouters P, Weekers F, Verwaest C, Bruyninckx F, Schetz M, Vlasselaers D, Ferdinande P, Lauwers P, Bouillon R: Intensive insulin therapy in the critically ill patients. N Engl J Med 2001, 345(19):1359-1367.

8. Griesdale DE, de Souza RJ, van Dam RM, Heyland DK, Cook DJ, Malhotra A, Dhaliwal R, Henderson WR, Chittock $D R$, Finfer S, Talmor D: Intensive insulin therapy and mortality among critically ill patients: a meta-analysis including NICE-SUGAR study data. Cmaj 2009, 180(8):821-7.

9. Bagshaw SM, Bellomo R, Jacka MJ, Egi M, Hart GK, George C, ANZICS CORE Management Committee: The impact of early hypoglycemia and blood glucose variability on outcome in critical illness. Crit Care 2009, 13(3):R91.

10. Krinsley JS, Keegan MT: Hypoglycemia in the critically ill: how low is too low? Mayo Clin Proc 2010, 85(3):215-216.

11. Lin J, Lee D, Chase JG, Shaw GM, Le Compte A, Lotz T, Wong J, Lonergan T, Hann CE: Stochastic modelling of insulin sensitivity and adaptive glycemic control for critical care. Comput Methods Programs Biomed 2008, 89(2):141-152 
12. Chase JG, Le Compte AJ, Suhaimi F, Shaw GM, Lynn A, Lin J, Pretty CG, Razak N, Parente JD, Hann CE, et al: Tight glycemic control in critical care-the leading role of insulin sensitivity and patient variability: a review and model-based analysis. Comput Methods Programs Biomed 2011, 102(2):156-171.

13. Pretty CG, Le Compte AJ, Chase JG, Shaw GM, Preiser JC, Penning S, Desaive T: Variability of insulin sensitivity during the first 4 days of critical illness: Implications for tight glycaemic control. Annals of Intensive Care 2012, 2(1):17.

14. Chase J, Shaw GM, Wong XW, Lotz T, Lin J, Hann CE: Model-based glycaemic control in critical care - A review of the state of the possible. Biomedical Signal Processing and Control 2006, 1(1):3-21.

15. Chase JG, Shaw GM, Lotz T, LeCompte A, Wong J, Lin J, Lonergan T, Willacy M, Hann CE: Model-based insulin and nutrition administration for tight glycaemic control in critical care. Curr Drug Deliv 2007, 4(4):283-296.

16. Morris AH, Orme J Jr, Truwit JD, Steingrub J, Grissom C, Lee KH, Li GL, Thompson BT, Brower R, Tidswell M, et al: A replicable method for blood glucose control in critically III patients. Crit Care Med 2008, 36(6):1787-1795.

17. Plank J, Blaha J, Cordingley J, Wilinska ME, Chassin L, Morgan C, Squire S, Haluzik M, Kremen J, Svacina S, et al: Multicentric, randomized, controlled trial to evaluate blood glucose control by the model predictive control algorithm versus routine glucose management protocols in intensive care unit patients. Diabetes Care 2006, 29(2):271-276.

18. Penning S, Le Compte AJ, Moorhead KT, Desaive T, Massion P, Preiser JC, Shaw GM, Chase JG: First pilot trial of the STAR-Liege protocol for tight glycemic control in critically ill patients. Comput Methods Programs Biomed 2011, Aug 30 [in press].

19. Lin J, Razak NN, Pretty CG, Le Compte A, Docherty P, Parente JD, Shaw GM, Hann CE, Geoffrey Chase J: A physiological Intensive Control Insulin-Nutrition-Glucose (ICING) model validated in critically ill patients. Comput Methods Programs Biomed 2011, 102(2):192-205.

20. Hann CE, Chase JG, Lin J, Lotz T, Doran CV, Shaw GM: Integral-based parameter identification for long-term dynamic verification of a glucose-insulin system model. Comput Methods Programs Biomed 2005, 77(3):259-270.

21. Evans A, Shaw GM, Le Compte A, Tan CS, Ward L, Steel J, Pretty CG, Pfeifer L, Penning S, Suhaimi F, et al: Pilot proof of concept clinical trials of stochastic targeted (STAR) glycemic control. Ann Intensive Care 2011, 1:38

22. Preiser JC, Devos P, Ruiz-Santana S, Melot C, Annane D, Groeneveld J, lapichino G, Leverve X, Nitenberg G, Singer $P$, et al: A prospective randomised multi-centre controlled trial on tight glucose control by intensive insulin therapy in adult intensive care units: the Glucontrol study. Intensive Care Med 2009, 35(10):1738-1748.

doi:10.1186/1475-925X-11-58

Cite this article as: Penning et al: Second pilot trials of the STAR-Liege protocol for tight glycemic control in critically ill patients. BioMedical Engineering OnLine 2012 11:58.

\section{Submit your next manuscript to BioMed Central and take full advantage of:}

- Convenient online submission

- Thorough peer review

- No space constraints or color figure charges

- Immediate publication on acceptance

- Inclusion in PubMed, CAS, Scopus and Google Scholar

- Research which is freely available for redistribution

Submit your manuscript at www.biomedcentral.com/submit 